\title{
Targeting mTOR in RET mutant medullary and differentiated thyroid cancer cells
}

\author{
Matti L Gild ${ }^{1, *}$, Iñigo Landa ${ }^{1, *}$, Mabel Ryder ${ }^{1,2}$, Ronald A Ghossein ${ }^{3}$, Jeffrey A Knauf ${ }^{1}$ \\ and James A Fagin ${ }^{1,2}$ \\ ${ }^{1}$ Human Oncology and Pathogenesis Program, ${ }^{2}$ Department of Medicine, and ${ }^{3}$ Department of Pathology, \\ Memorial Sloan-Kettering Cancer Center, 1275 York Avenue, PO Box 296, Zuckerman Building, ZRC 504, New York, \\ New York 10065, USA \\ *(M L Gild and I Landa contributed equally to this work)
}

\author{
Correspondence \\ should be addressed \\ to J A Fagin \\ Email \\ faginj@mskcc.org
}

\begin{abstract}
Inhibitors of RET, a tyrosine kinase receptor encoded by a gene that is frequently mutated in medullary thyroid cancer, have emerged as promising novel therapies for the disease. Rapalogs and other mammalian target of rapamycin (mTOR) inhibitors are effective agents in patients with gastroenteropancreatic neuroendocrine tumors, which share lineage properties with medullary thyroid carcinomas. The objective of this study was to investigate the contribution of mTOR activity to RET-induced signaling and cell growth and to establish whether growth suppression is enhanced by co-targeting RET and mTOR kinase activities. Treatment of the RET mutant cell lines TT, TPC-1, and MZ-CRC-1 with AST487, a RET kinase inhibitor, suppressed growth and showed profound and sustained inhibition of mTOR signaling, which was recapitulated by siRNA-mediated RET knockdown. Inhibition of mTOR with INK128, a dual mTORC1 and mTORC2 kinase inhibitor, also resulted in marked growth suppression to levels similar to those seen with RET blockade. Moreover, combined treatment with AST487 and INK128 at low concentrations suppressed growth and induced apoptosis. These data establish mTOR as a key mediator of RET-mediated cell growth in thyroid cancer cells and provide a rationale for combinatorial treatments in thyroid cancers with oncogenic RET mutations.
\end{abstract}

\section{Key Words}

- medullary thyroid carcinoma

- oncogenic RET

- mTOR

- RET inhibitors

- mTOR inhibitors

- drug combinations

\section{Introduction}

RET is a tyrosine kinase receptor for neurotrophic ligands belonging to the glial cell line-derived neurotrophic factor family that regulates growth, survival, differentiation, and migration of cells of neural crest origin (Airaksinen \& Saarma 2002). RET also plays a crucial role in thyroid tumorigenesis. Mutations in RET are highly prevalent in medullary thyroid carcinomas (MTCs), which stem from the parafollicular cells of the thyroid gland, and may occur as sporadic or hereditary tumors. Almost all hereditary
MTC syndromes are caused by constitutively activating germline RET point mutations and can present as part of the multiple endocrine neoplasia syndromes MEN2A and MEN2B or as familial MTCs. Somatic RET mutations are found in up to $50 \%$ of the sporadic forms of the disease. $R E T$ is also mutated in papillary thyroid cancers through somatic recombination events generating the RET/PTC family of fusion oncoproteins, in which the kinase domain of RET is constitutively active.

Published by Bioscientifica Ltd. 
Upon activation, RET is autophosphorylated on numerous tyrosine residues, and the signaling pathways activated in response to this have been studied quite extensively (de Groot et al. 2006, Castellone \& Santoro 2008). Phosphorylation of RET-Y1062 generates a docking site for the adaptor molecule Src-Homology 2 (Shc), which when engaged recruits effectors that lead to activation of MAPK and phosphoinositol 3-kinase (PI3K) signaling. Inhibition of the PI3K pathway with LY294002, a kinase inhibitor that also has effects on mammalian target of rapamycin (mTOR), has been shown to inhibit growth and induce apoptosis of the MTC cell line TT (Kunnimalaiyaan et al. 2006, Ball et al. 2007). Recently, novel natural compounds called withanolides have been shown to induce apoptosis in MTC cell lines at high concentrations, which was suggested to be due to dual mTOR and RET inhibition (Samadi et al. 2012). MAPK pathway inhibitors have only modest effects on growth of RET/PTC1 mutant thyroid cancer cells (Ball et al. 2007, Leboeuf et al. 2008) and RET mutant MTC cells (Koh et al. 2012).

The mTOR kinase is a component of the PI3K signaling pathway that regulates protein synthesis, metabolism, and cell growth in response to growth factors and nutrients. mTOR is present in two multi-protein complexes: mTORC1, in which it is associated with Raptor, and which controls cap-dependent translation, and mTORC2, in which the kinase is associated with Rictor, and which phosphorylates AKT at serine 473 leading to enhancement of its catalytic activity (Sarbassov et al. 2005). mTORC1 is sensitive to rapamycin, whereas mTORC2 is not. Alternatively, mTOR can be activated through ERK/GSK and AMPK signaling pathways.

There is clear evidence that mTOR is dysregulated in pancreatic neuroendocrine tumors (NETs). The mTORC1 inhibitor rapamycin inhibits growth of NET cells in vitro (Couderc et al. 2011), and one of its analogs, everolimus, was found to have significant activity in a clinical trial of patients with pancreatic NETs (Yao et al. 2011). MTC cells arise from $\mathrm{C}$ cells and therefore derive from a neuroendocrine lineage. Interestingly, the growth of at least one MTC cell line, TT cells, is also mTOR dependent (Grozinsky-Glasberg et al. 2010).

MTC has a disproportionately high mortality compared with most other types of thyroid cancer, with early surgery offering the only chance for curative therapy. Vandetanib (AZD6474) and cabozantinib (XL184) are ATP-competitive RET kinase inhibitors that were recently approved for treatment of metastatic medullary thyroid cancer by the FDA based on significant extension of progression-free survival in patients with familial or sporadic forms of the disease (Kurzrock et al. 2011, Wells et al. 2012). Other ATP-competitive small-molecule RET kinase inhibitors, such as sorafenib, are currently in clinical trials and are showing promising results in patients with metastatic MTC (Lam et al. 2010). However, while this is exciting new data, these compounds are associated with significant side effects and patients often require dose reductions. Low-dose therapy with vandetanib has also shown evidence of efficacy (Robinson et al. 2010), although the extent to which the activity of the oncogenic kinase is inhibited in the MTC lesions with the lower dose of this drug is uncertain.

The goals of this study were to determine whether oncogenic RET regulates mTOR activity in MTC and PTC cells and whether targeted inhibition of these two kinases shows cooperative effects on growth suppression. mTOR activity was exquisitely RET-dependent in all cell lines tested. Treatment of RET mutant thyroid cancer cell lines with the RET kinase inhibitor NVP-AST487 profoundly inhibited their growth. Similar effects were noted when these cells were treated with the mTOR kinase inhibitor INK128. However, their combination at high concentrations showed no additive effect, pointing to a possible common mechanism of action. Indeed, when combined at lower concentrations, the RET and mTOR kinase inhibitors showed strong cooperativity. These results indicate a critical role of mTOR signaling in RET-induced cell growth and provide strategies to maximize therapeutic effects when toxicity precludes using RET kinase inhibitors at their maximally effective dose.

\section{Materials and methods}

\section{Cell lines and culture conditions}

TT cells, derived from an MTC with a $R E T^{\mathrm{C} 634 W}$ mutation, were from the American Type Culture Collection (Manassas, VA, USA). MZ-CRC-1 cells were derived from a malignant pleural effusion from a patient with metastatic MTC with a $R E T^{\mathrm{M} 918 T}$ mutation. TPC-1 cells harbor the RET-PTC1 rearrangement that consists of a fusion gene between RET and CCDC6. All three cell lines have been genetically fingerprinted by either single-nucleotide polymorphismcomparative genome hybridization (SNP-CGH) or polymorphic short tandem repeat and verified to be unique (Schweppe et al. 2008, Dadon et al. 2013). TT cells were grown in F12 Ham's media supplemented with 10\% fetal bovine serum (FBS, Fisher Scientific, Pittsburgh, PA, USA). MZ-CRC-1 cells were grown in DMEM supplemented with

Published by Bioscientifica Ltd. 
10\% FBS. TPC-1 cells were grown in DMEM-High Glucose media supplemented with 5\% FBS. The human thyroid carcinoma cell lines FTC133 and SW1736 were grown in F12 Ham's:DMEM (1:1) with 10\% FBS and in RMPI-1640 with 10\% FBS and 1\% non essential amino acids respectively. All media were supplemented with glutamine and 100 units/ml penicillin-streptomycin unless specified.

\section{Reagents}

NVP-AST487-NX ('AST487' from now on), a protein tyrosine kinase inhibitor with the structure 1-[4-(4ethyl-piperazin-1-ylmethyl)-3-trifluoromethyl-phenyl]3-[4-(6-methylamino-pyrimidin-4-yloxy)-phenyl]-urea, was synthesized at Novartis Pharma AG. It inhibits the ICD of the RET kinase with an $\mathrm{IC}_{50}$ of $0.88 \mu \mathrm{l} / 1$ (Akeno-Stuart et al. 2007). INK128 is an ATP-competitive inhibitor of mTOR complex 1 and complex 2 . Of a panel of 222 protein kinases, it inhibited five kinases (including mTOR) $>80 \%$ at $1 \mathrm{mM}$ (SelectScreen Kinase Profiling, Life Technologies) and had very low activity on RET (Intellikine, La Jolla, CA, USA) (Maiso et al. 2011). The following rabbit antibodies were purchased from Cell Signaling Technology (Beverly, MA, USA): anti-phospho-Akt XP (Ser473, \#4060), anti-Akt (\#2938), anti-phospho-MEK1/2 (Ser217/221,\#9121), anti-phospho-ERK1/2 (Thr202/Tyr204, \#9101), anti-ERK1/2 (\#4695), anti-phospho-S6 ribosomal protein (Ser235/236, \#2211), anti-phospho-4EBP-1 (\#9455), anti-4EBP-1 (\#9452), anti-phospho-RET (Y905 \#3221), and anti-RET (\#3220). The mouse anti-cleaved PARP (\#9544) and anti-S6 ribosomal protein (\#2317) were also from Cell Signaling. Rabbit anti-antiphosphatidylinositol 3-kinase (PI3K- p85 \#06-195, Millipore, Billerica, MA, USA) and mouse anti- $\beta$-actin (\#A2228, Sigma) were also employed. Secondary antibodies were from GE Healthcare (Pittsburgh, PA, USA).

\section{Western blotting}

Protein content of cell lysates was assessed by the BCA protein assay (Thermo Scientific, Rockford, IL, USA) and subjected to western blotting. Briefly, cells were washed once with PBS and lysed in modified RIPA buffer consisting of $50 \mathrm{mM}$ Tris-HCl, $150 \mathrm{mM} \mathrm{NaCl}, 1 \% \mathrm{NP} 40$, $0.5 \%$ sodium deoxycholate, $0.1 \%$ SDS, and $1 \mathrm{mM}$ EDTA. Samples containing $20 \mu \mathrm{g}$ protein were separated by SDS-10\% PAGE for all antibodies except pRET and RET, for which SDS-7.5\% PAGE was utilized. Signal detection was through Immobilon Western Chemiluminescent HRP Substrate (Millipore) and images were analyzed with Molecular Imaging Software (Kodak).

\section{Proliferation assays}

TPC-1, MZ-CRC-1, and TT cells were plated in triplicate in six-well plates and treated with the indicated concentration of each compound. TPC-1 cells were collected by trypsinization and counted on day 4 . Because of their more prolonged doubling times, TT and MZ-CRC- 1 cells were retreated every 2-3 days and counted at 6 days. Cells were counted in a Vi-cell series cell viability analyzer (Beckman Coulter, Fullerton, CA, USA). The dose required to inhibit growth by $50 \%$ ( $\left.\mathrm{IC}_{50}\right)$ was calculated using GraphPad Prism version 5.02 for Windows (GraphPad Software, San Diego, CA, USA).

\section{RNA silencing}

Silencer Predesigned-Validated siRNAs were purchased from Life Technologies. Cells were plated in antibioticfree media at $30 \%$ confluence. The following day, they were transfected with Lipofectamine RNAImax (Life Technologies) and siRNAs to RET (Ambion, Austin, TX, USA; \#4392420) or a scrambled control (Scramble sequence, Applied Biosystems, \#AM4611). Media were changed $6 \mathrm{~h}$ later and incubation with compounds commenced as specified.

\section{Cell cycle analysis}

Cells were plated at $1 \times 10^{6}$ and $2 \times 10^{6}$ cells/well in triplicate. The following day, cells were incubated with fresh medium with vehicle, INK128, AST487, or the compounds in combination. Cells were collected at 72 and $96 \mathrm{~h}$ and treated with $20 \mathrm{mg} / \mathrm{ml}$ Purelink RNAse A (Invitrogen) and $10 \mathrm{mg} / \mathrm{ml}$ ethidium bromide (Promega). Following 1-h incubation, cells were retreated with ethidium bromide and cell cycle analysis was performed on a FACSCalibur flow cytometer (BectonDickinson, Franklin Lakes, NJ, USA).

\section{Animal studies}

Tg-RET/PTC3 transgenic mice were kindly provided by Dr Jay Rothstein (Amgen, Inc., Seattle, WA, USA). These mice express the RET/PTC3 oncoprotein in thyroid follicular cells under the control of the thyroglobulin gene promoter and develop solid-variant papillary thyroid cancers (Powell et al. 1998). Five-week-old Tg-RET/PTC3 mice were treated once daily by oral gavage with AST 487 at $50 \mathrm{mg} / \mathrm{kg}$ or INK1 28 at $3 \mathrm{mg} / \mathrm{kg}$ for 5 days a week for 2 weeks. AST 487 was

Published by Bioscientifica Ltd. 
reconstituted in $\mathrm{N}$-methyl-2-pyrrolidone (NMP) and polyethylene glycol 300 at a 1:10 ratio and made up fresh daily for each treatment. INK128 was dissolved in NMP and added to pre-dissolved polyvinylpyrrolidone in water, vortexed, and kept at room temperature. Mice were killed at day $14,6 \mathrm{~h}$ after the last oral gavage. Thyroids were removed and placed immediately in $4 \%$ paraformaldehyde and incubated overnight at $4{ }^{\circ} \mathrm{C}$. Tissue was then washed twice in PBS and kept at $4{ }^{\circ} \mathrm{C}$ in $70 \%$ ethanol. The fixed tissue was embedded in paraffin and sectioned into $5 \mu \mathrm{M}$ sections. The H\&E-stained slides were reviewed by a pathologist (R A G) experienced in the analysis of murine thyroid cancers. Tissue was deparaffinized and immunostained with antibodies to Ki67 (VP-K541, Vector Laboratories, Burlingame, CA, USA) and phospho-S6 ribosomal protein (\#2211, Cell Signaling Technology) at the Memorial Sloan Kettering Cancer Center Molecular Cytology Core Facility. Quantification of staining was performed using whole thyroid digitized images obtained from scanned slides and analyzed with Metamorph Software (Molecular Devices, Sunnyvale, CA, USA).

\section{Results}

The RET kinase inhibitor AST487 decreases cell proliferation and mTOR signaling in RET mutant cell lines

AST487 inhibited growth of all three thyroid cancer cell lines with $\mathrm{IC}_{50}$ in the low nanomolar range (Fig. 1A). The compound also inhibited RET phosphorylation in a dose-dependent manner (Fig. 1B). We next determined the effects of AST487 on downstream targets of mTORC1 and mTORC2. As shown in Fig. 1B, phosphorylation of the mTORC1 substrate 4EBP1, and of ribosomal S6, which is phosphorylated by the mTORC1 substrate p70-S6 kinase, was inhibited in a dose-dependent manner by AST487 in all RET mutant cell lines. These effects were detected even at very low concentrations of the RET kinase inhibitor (as low as $5 \mathrm{nM}$ ) and showed a tight association with inhibition of mTOR kinase substrates (Fig. 1C). In contrast, mTOR effectors were not inhibited by AST487 in the FTC133 cell line, which harbors a homozygous PTEN loss-of-function mutation and is wild type for RET (Fig. 1D). To confirm that the effects on the mTOR
A

\begin{tabular}{cc}
\hline & IC $_{50} \pm$ S.E.M. \\
& AST487 (nM) \\
\hline TPC-1 & $1.63 \pm 0.29$ \\
TT & $3.12 \pm 0.08$ \\
MZ-CRC-1 & $41.30 \pm 0.23$
\end{tabular}

C

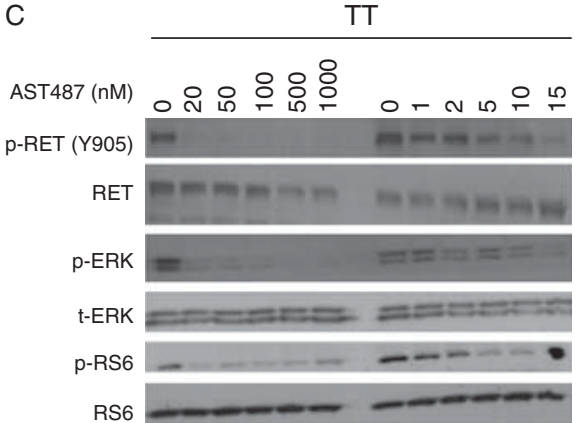

B

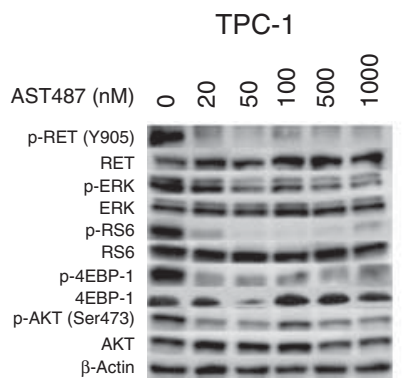

TT

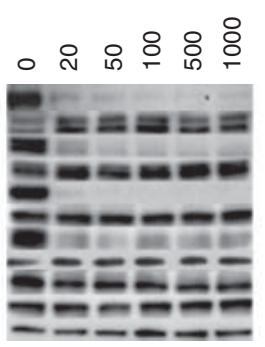

$\mathrm{MZ}-\mathrm{CRC}-1$

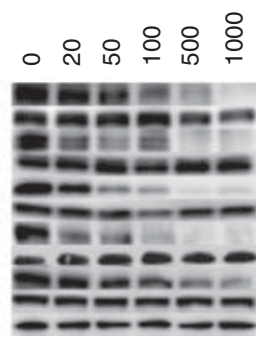

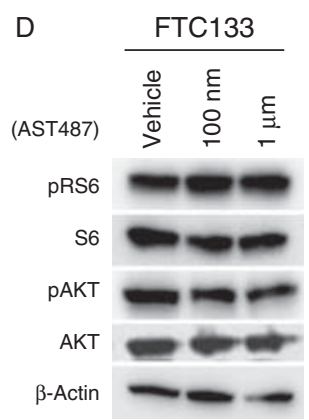

E
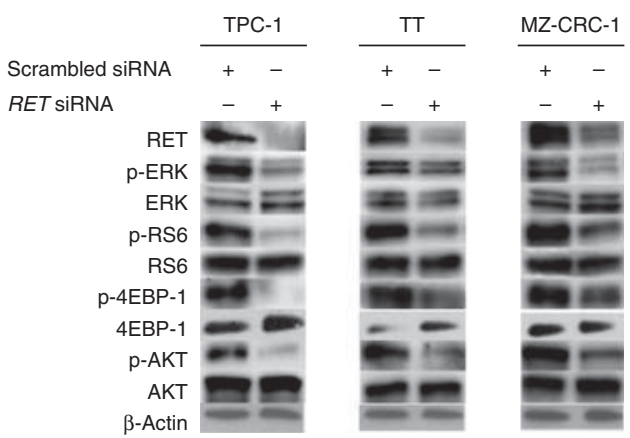

\section{Figure 1}

Inhibition of RET decreases growth and mTOR signaling in thyroid cancer cell lines with endogenous $R E T$ mutations. (A) $I_{50}(n M)$ for the RET kinase inhibitor AST487 in the indicated thyroid cancer cell lines. (B) Western blots of lysates of cell lines treated with the indicated concentrations of AST487 for $24 \mathrm{~h}$ probed with the indicated antibodies.

http://erc.endocrinology-journals.org DOI: 10.1530/ERC-13-0085
(C) 2013 Society for Endocrinology Printed in Great Britain
(C) Western blots of lysates of TT cells treated with high and low concentrations of AST487 for $24 \mathrm{~h}$ probed with the indicated antibodies. (D) Western blots of lysates of FTC133 cell line treated with AST487. (E) Knock down of RET with siRNA inhibits downstream targets of mTOR. Cell lines were lysed $72 \mathrm{~h}$ after transfection. 
pathway were due to RET inhibition, we knocked down RET with siRNA. Optimal concentrations for knockdown were different between the cell lines and the best effects without toxicity were utilized. For each experiment, the appropriate concentration of a scrambled siRNA was used as control. At $72 \mathrm{~h}$ post transfection, when RET knockdown was maximal, there was clear inhibition of the downstream targets of mTOR (Fig. 1E).

\section{Inhibition of mTOR kinase activity inhibits MTC cell growth}

The contribution of mTOR to growth of RET mutant thyroid cancer cell lines was assessed by treatment with INK128, a kinase inhibitor that blocks mTORC1 and mTORC2 activities. As shown in Fig. 2A, growth of all cell lines tested was inhibited with an $\mathrm{IC}_{50}$ of between 10 and $20 \mathrm{nM}$. INK128 profoundly inhibited RS6 and 4EBP1 phosphorylation at low nanomolar concentrations (Fig. 2B), without the feedback upregulation of pAKT seen with mTORC1 inhibitors (Fig. 2C). INK128 had no effect on RET autophosphorylation in MZ-CRC-1 (Fig. 2D).

\section{Pharmacological inhibition of RET and mTOR shows synergy at low concentrations}

Although growth of TT and TPC-1 cells was markedly inhibited by $100 \mathrm{nM}$ INK128, $100 \mathrm{nM}$ AST487 was more potent, inducing cytostatic effects on TPC-1 cells and cytotoxic effects on TT cells (Fig. 3A). Combined administration of $100 \mathrm{nM}$ AST487 (>50-fold $\mathrm{IC}_{50}$ ) and $100 \mathrm{nM}$ INK128 (five- to tenfold $\mathrm{IC}_{50}$ ) did not augment the inhibition of cell growth above that seen with AST487 alone (Fig. 3A). This is probably because at this concentration, AST487 already inhibits mTOR signaling profoundly. It is not clear from the clinical trials with multi-kinase ATP competitors whether full inhibition of RET kinase activity can be achieved at the maximal tolerated doses. Because of this, we next examined the effects of lower concentrations of AST487 and INK128 (at or close to the $\mathrm{IC}_{50}$ for each cell line), alone or in combination, on growth and signaling. Combination treatment showed greater growth inhibition in the RET mutant cell lines compared with that seen with each compound alone (Fig. 3B). When used at these lower concentrations, AST487 $(2 \mathrm{nM})$ and INK128 (5 nM) blocked mTOR signaling partially, whereas the combination showed a more profound inhibition, particularly of the direct mTOR substrate 4EBP1 (Fig. 3C).

\section{Knockdown of RET cooperates with the mTOR kinase inhibitor INK128 in growth suppression of RET mutant thyroid cell lines}

To better define the role of mTOR in RET-dependent growth and signaling, we looked at the combined effects of RET siRNA-mediated knockdown and INK128. Effects on

\begin{tabular}{cc}
\hline & IC $_{50} \pm$ S.E.M. \\
& INK128 $(\mathrm{nM})$ \\
\hline TPC-1 & $11.02 \pm 0.22$ \\
TT & $18.29 \pm 0.13$ \\
MZ-CRC-1 & $23.10 \pm 0.09$ \\
\hline
\end{tabular}

C

TPC-1

INK128 (500 nM) Time (h)

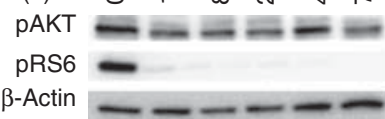

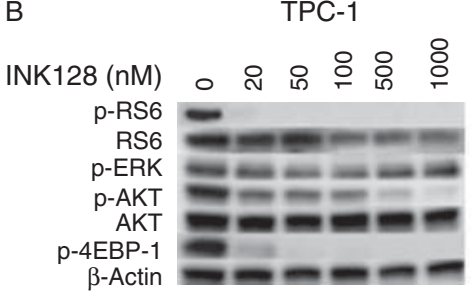

TT

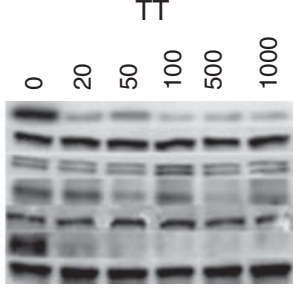

MZ-CRC-1

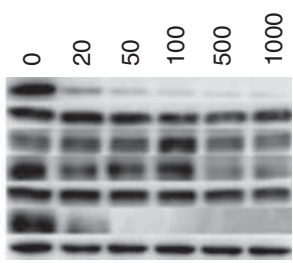

D

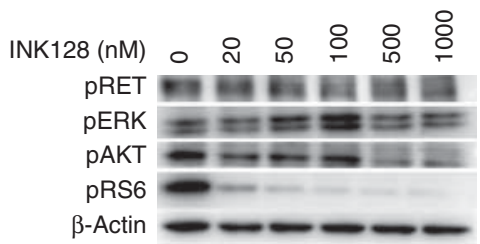

\section{Figure 2}

The mTOR kinase inhibitor INK128 decreases the proliferation of RET mutant thyroid cancer cell lines and inhibits downstream targets of mTOR. (A) IC 50 (nM) for INK128. (B) Cell lines were treated with the indicated concentrations of INK 128 for $24 \mathrm{~h}$ and western blots probed with the indicated antibodies. Total ERK and 4E-BP1 were not assessed. (C) INK128 induces sustained inhibition of AKT and RS6 phosphorylation in TPC-1 $(500 \mathrm{nM})$ and TT cells (100 nM). (D) INK128 does not inhibit RET phosphorylation. MZ-CRC-1 cells were incubated for $24 \mathrm{~h}$ with the indicated concentrations of INK128. http://erc.endocrinology-journals.org DOI: 10.1530/ERC-13-0085
(C) 2013 Society for Endocrinology Printed in Great Britain
Published by Bioscientifica Ltd. 
A

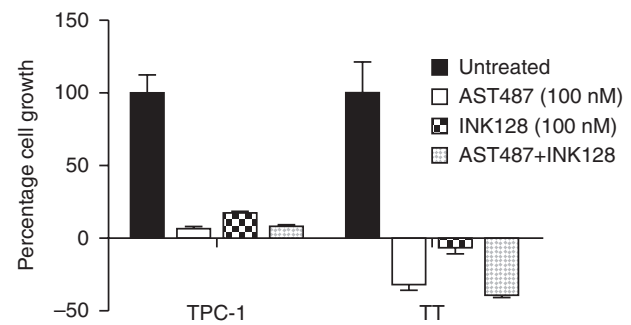

B

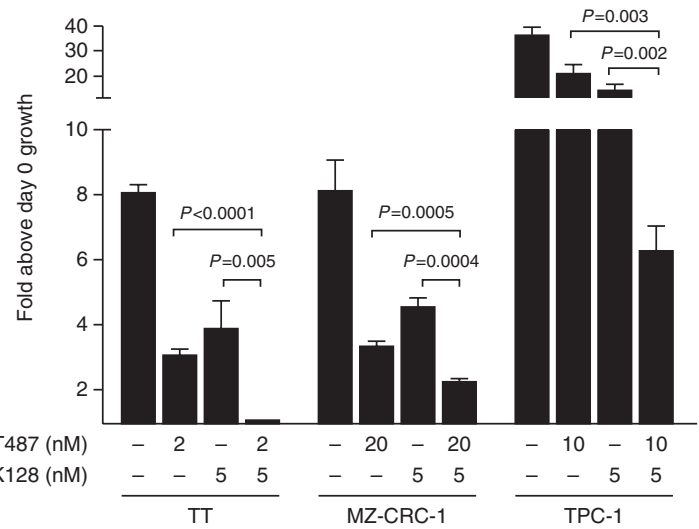

C
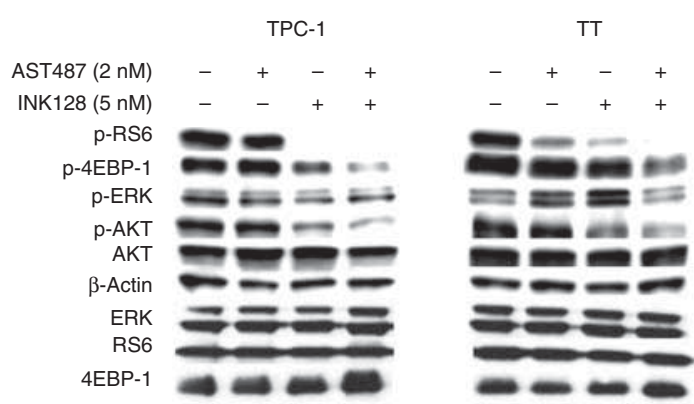

Figure 3

Combined treatment with submaximal concentrations of the RET and mTOR kinase inhibitors cooperate to inhibit mTOR signaling and cell growth. (A) TPC-1 and TT cells were treated with $100 \mathrm{nM}$ INK128, $100 \mathrm{nM}$ AST487, or both. Data represents percent of inhibition compared with vehicle-treated controls. (B) TPC-1, TT, and MZ-CRC-1 cells were treated with the indicated concentrations of AST487 and INK128 for 4 (TPC-1) and 16 days (MZ-CRC-1 and TT) prior to cell counting. Data represents fold-cell number above that on day 0 . (C) Western blots of TPC-1 and TT cells treated with $2 \mathrm{nM}$ AST487 and/or $5 \mathrm{nM}$ INK128 for $24 \mathrm{~h}$ probed with the indicated antibodies.

growth were only evaluated in TPC- 1 cells, as the growth rate of TT and MZ-CRC cells was too slow to test the effects of RNA interference because of the transient knockdown of RET. Cells were treated with or without $2 \mathrm{nM}$ INK128 1 day following transfection. RET knockdown markedly inhibited TPC-1 cell growth, which was further inhibited by $100 \mathrm{nM}$ INK128 (Fig. 4A). The cooperative effects on signaling are shown in Fig. 4B. Here, cells were exposed to $2 \mathrm{nM}$ INK128 for $4 \mathrm{~h}$ the day after transfection with the
RET siRNA. Levels of phosphorylated ribosomal S6 were further blunted with dual treatment.

\section{Combination therapy enhances apoptosis in medullary thyroid cancer cell lines}

Treatment with $100 \mathrm{nM}$ AST487 for $96 \mathrm{~h}$ induced apoptosis of TT cells, manifesting as an increase in the population of cells with a $<2 \mathrm{~N}$ DNA content (i.e. sub-G1) as determined by FACS. A similar trend was observed in MZ-CRC cells, although the effects were of lesser magnitude (Fig. 5A). TPC-1 cells treated with $100 \mathrm{nM}$ AST487-exhibited G1 arrest, but no cell death occurred, whereas in cell lines with wild-type RET (SW1736), there was no effect on viability (data not shown). INK128 did not increase the sub-G1 fraction in any of the cell lines, whereas it markedly enhanced the apoptotic effects of the RET kinase inhibitor. These effects were particularly striking in TT cells, where the abundance of cleaved PARP was markedly greater in cells treated with $100 \mathrm{nM}$ of both compounds (Fig. 5B).

\section{Treatment of Tg-RET/PTC3 mice with INK128 or AST487 is associated with reduced thyroid cell proliferation}

Five-week-old $T g$-RET/PTC3 mice were treated with vehicle, INK128 (3 mg/kg), or AST487 $(50 \mathrm{mg} / \mathrm{kg})$ via oral gavage for 2 weeks. Thyroids were harvested $6 \mathrm{~h}$ after the final dose. Immunohistochemistry demonstrated similar reductions in phospho-ribosomal S6 staining following both treatments (Fig. 6). The proliferation index, as determined by Ki67 staining, was reduced by both drugs (AST487>INK128). As the penetrance of PTC in this model is variable, it was not possible to determine the effects on tumor phenotype in a rigorous manner. However, in the AST487 treatment group, a consistent regression of tumor phenotype was observed (Fig. 6). Combination therapy failed to demonstrate an additive effect by virtue of the potent effects of each compound used alone. Lower doses of each were attempted but the results were inconclusive, in part because of the variable penetrance of the disease.

\section{Discussion}

Multi-kinase inhibitors, such as vandetanib and cabozantinib, are new therapeutic options for patients with metastatic MTC. Besides RET, vandetanib also inhibits EGFR and VEGFR kinase activities. Its mechanism of action in MTC patients is unclear, although it appears that patients with RET mutations may be preferentially

Published by Bioscientifica Ltd. 
A

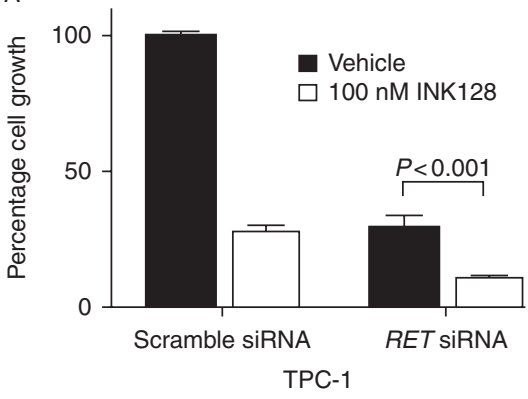

B

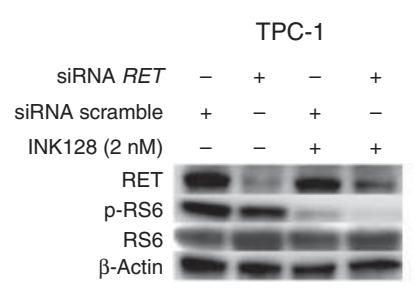

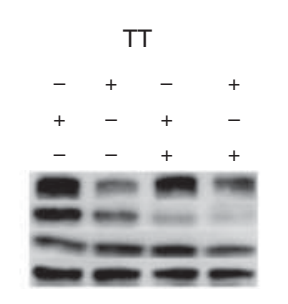

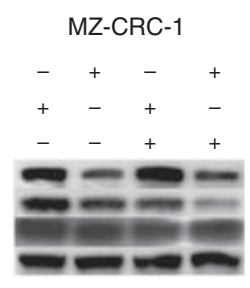

Figure 4

RET knockdown cooperates with INK128 to inhibit downstream targets of mTOR. (A) TPC-1 cells were treated with scrambled or RET siRNA. INK128 $(100 \mathrm{nM})$ was added at $6 \mathrm{~h}$ post transfection INK128. Cells were counted at $96 \mathrm{~h}$ on the Vi-cell. (B) TPC-1 and MZ-CRC-1 cells were treated with

responsive to the compound (Wells et al. 2012). In the phase 3 trial, $12 \%$ of patients discontinued the drug, primarily due to adverse effects, and 35\% required dose reductions (Wells et al. 2012). Although lower doses of the drug appear to exert a therapeutic benefit (Robinson et al. 2010), we do not know whether RET kinase activity is maximally inhibited with either dose, or to what extent the activity of the driver kinase needs to be blocked to obtain a biological effect.

Rapa et al. (2011) observed intense IHC positivity for phospho-Akt, phospho-mTOR, and phospho-p70S6K in MTCs, which was positively correlated with the presence of germline mutations of RET, whereas cancers with somatic RET mutations had a more heterogeneous pattern of staining, for reasons that were not investigated. In the same study, the medullary cancer cell line TT was found to be growth inhibited by the mTORC1 inhibitor everolimus, a finding that confirmed an earlier report (Grozinsky-Glasberg et al. 2010). Jin et al. (2011) also found that TT cells were inhibited by the dual PI3K/mTOR kinase inhibitor BEZ235 and that the inhibition was synergistic with RAF265, a RAF kinase inhibitor that the authors reported inhibited RET phosphorylation at low nanomolar concentrations.

To our knowledge, the experiments described here are the first demonstration that the activity of mTOR is dependent on RET in thyroid cancer cells with endogenous mutations of the oncogene, derived either from $\mathrm{C}$ cells or from thyroid follicular cells. We acknowledge that further confirmation of the mTOR dependence of RET signaling and cell growth would require rescuing MTC viability by constitutively activating mTOR distal to RET in the presence of the RET kinase inhibitor. These experiments were attempted with constitutively activated mutants of AKT1 and were not informative (results not scrambled or RET siRNA for $48 \mathrm{~h}$ and then with $2 \mathrm{nM}$ INK128 or vehicle for $4 \mathrm{~h}$. TT cells were treated with scrambled or RET siRNA for $96 \mathrm{~h}$, followed by $2 \mathrm{nM}$ INK 128 for $4 \mathrm{~h}$.

shown). Nevertheless, it should be noted that inhibition of mTOR signaling was shown with a potent RET inhibitor that has no direct effects on components of the PI3K-AKTmTOR pathway, as well as by knockdown of RET by RNA interference. As MTC cells are addicted to RET, and its effects are mediated by mTOR, the dose reductions of RET kinase inhibitors such as vandetanib and sorafenib that
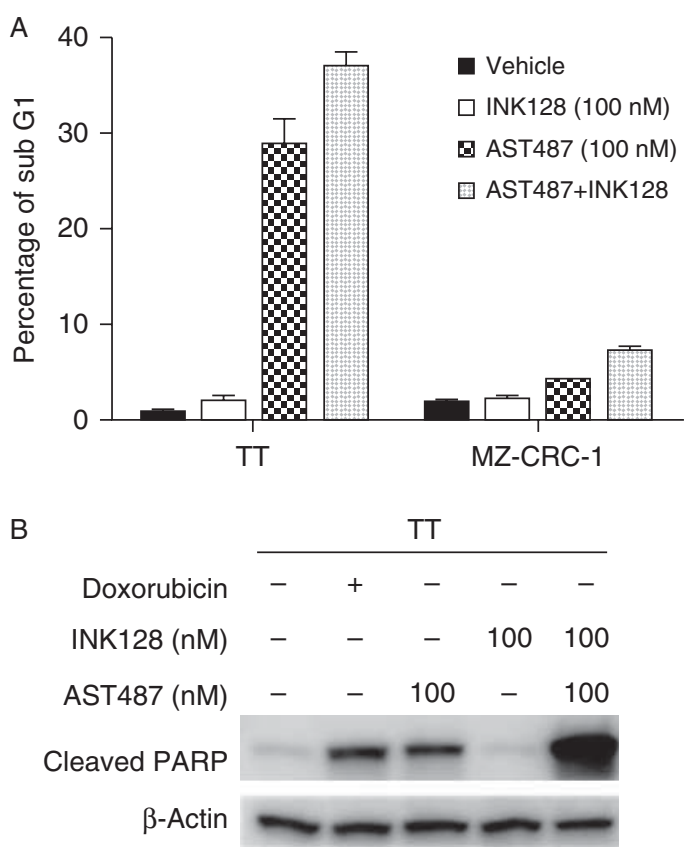

Figure 5

(A) AST487-induced apoptosis of TT and MZ-CRC-1 cells is augmented by INK128. MZ-CRC-1 and TT cells were treated with $100 \mathrm{nM}$ INK128 and $100 \mathrm{nM}$ AST487, alone or in combination, for $96 \mathrm{~h}$ prior to FACS analysis. Data represents the percentages of cells at sub G1 stages. (B) TT cells were treated with the indicated concentration of compounds for $72 \mathrm{~h}$. Western blots were probed for cleaved PARP.

Published by Bioscientifica Ltd. 

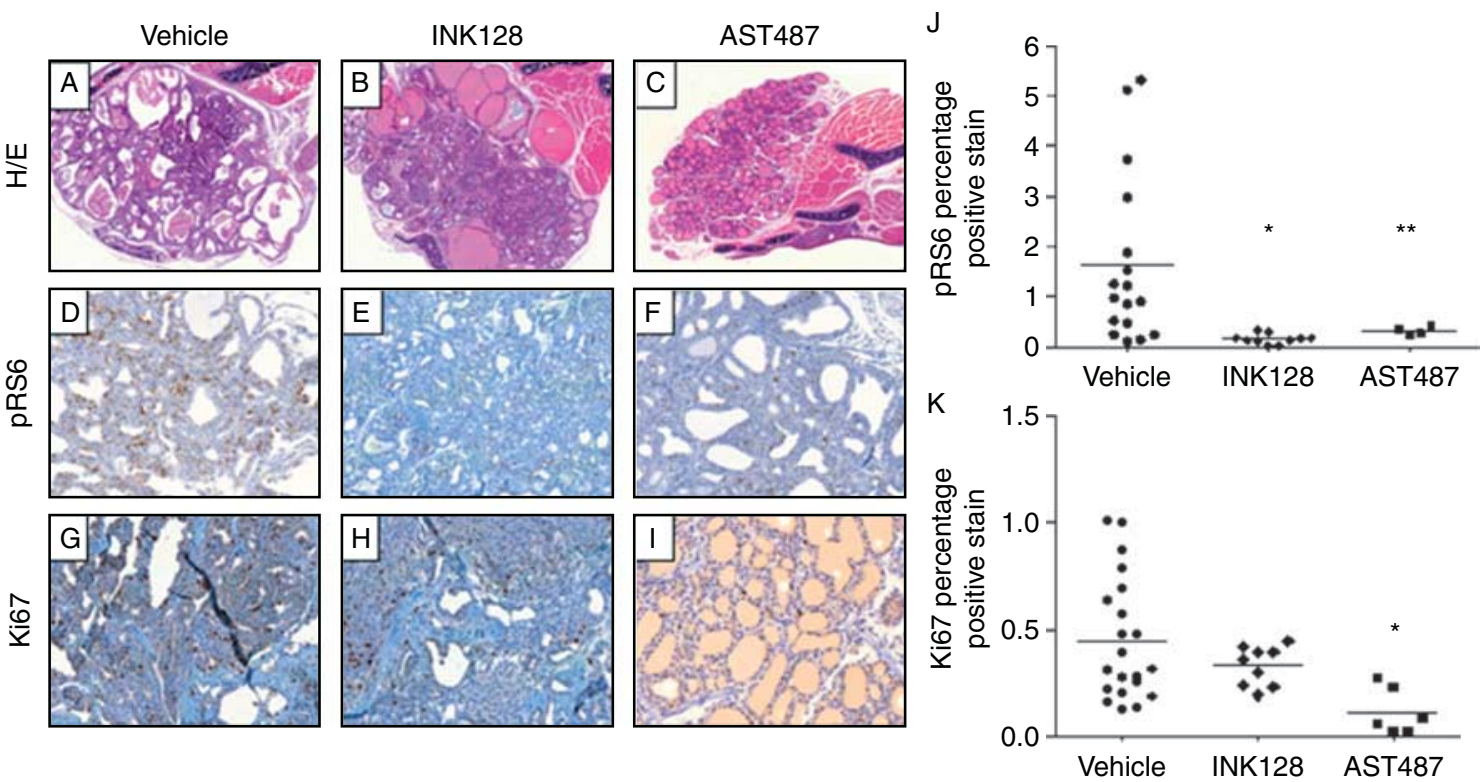

\section{Figure 6}

Treatment of PTCs from Tg-RET/PTC3 mice with either INK128 or AST487 is associated with reduced $\mathrm{mTOR}$ signaling and a decreased mitotic index. Five-week-old Tg-RET/PTC3 mice were treated with vehicle, INK128 ( $3 \mathrm{mg} / \mathrm{kg}$ ), or AST487 $(50 \mathrm{mg} / \mathrm{kg}$ ) via oral gavage for 2 weeks. Thyroids were harvested $6 \mathrm{~h}$ after the final dose. (A, B, C, D, E, F, G, H, and I)

Representative sections for each indicated experimental arm: $(A, B$, and $C)$

are often required in patients with MTC may result in incomplete inhibition of the oncogenic receptor and of mTOR signaling. Indeed, when the RET kinase inhibitor was used at concentrations that were insufficient to inhibit mTOR signaling, addition of low-dose INK128 further suppressed the pathway and conferred greater inhibition of cell growth.

We used a mouse transgenic model of tumors of thyroid follicular cells driven by the RET/PTC3 fusion protein to examine the effects of these compounds in vivo. Treatment with AST487 profoundly inhibited the phosphorylation of ribosomal S6 kinase, as did INK128. Both compounds inhibited cell proliferation as determined by Ki67 staining, with the RET kinase showing a more potent effect. These results are consistent with the effects we observed in vitro and suggest that a component of the RET-driven oncogenic drive is transduced through pathways other than mTOR. Unfortunately, mouse genetic models of MTC have low and inconsistent penetrance and are therefore not ideally suited for preclinical experiments of this nature.

MTC cells belong to a family of tumors derived from neuroendocrine cells. The favorable response in patients with metastatic NETs to rapamycin analogs suggests that
H\&E. (D, E, and F) IHC with anti-pRS6. G, H, and I) IHC with Ki67. ( $J$ and K) Quantification of pS6K and Ki67 IHC using Metamorph image analysis software. Brown-labeled pixels representing positive stains were selected and assigned a threshold. The computer software then calculated the brown area and the total thyroid area. The $\%$ positive area was plotted. $* P<0.01 ; * * P<0.05$

mTOR dependency for growth may be a general property of these cancer cell lineages (Missiaglia et al. 2010, Yao et al. 2011). Our data provide a preclinical rationale to consider combination treatments with RET and mTOR inhibitors to maximally suppress the activity of this pathway.

\section{Declaration of interest}

The authors declare that there is no conflict of interest that could be perceived as prejudicing the impartiality of the research reported.

\section{Funding}

This project has been funded by R01-CA50706 and the Byrne fund.

\section{Author contribution statement}

M L Gild, M Ryder, I Landa, Jeffrey A Knauf, and J A Fagin designed experiments; M L Gild, M Ryder, and I Landa performed experiments; all analyzed data; M L Gild, I Landa, and J A Fagin wrote the paper.

\section{Acknowledgements}

The authors are grateful to Katti Jessen (formerly Intellikine) for providing INK128.

Published by Bioscientifica Ltd. 


\section{References}

Airaksinen MS \& Saarma M 2002 The GDNF family: signalling, biological functions and therapeutic value. Nature Reviews. Neuroscience $\mathbf{3}$ 383-394. (doi:10.1038/nrn812)

Akeno-Stuart N, Croyle M, Knauf JA, Malaguarnera R, Vitagliano D, Santoro M, Stephan C, Grosios K, Wartmann M, Cozens R et al. 2007 The RET kinase inhibitor NVP-AST487 blocks growth and calcitonin gene expression through distinct mechanisms in medullary thyroid cancer cells. Cancer Research 67 6956-6964. (doi:10.1158/0008-5472. CAN-06-4605)

Ball DW, Jin N, Rosen DM, Dackiw A, Sidransky D, Xing M \& Nelkin BD 2007 Selective growth inhibition in BRAF mutant thyroid cancer by the mitogen-activated protein kinase kinase 1/2 inhibitor AZD6244. Journal of Clinical Endocrinology and Metabolism 92 4712-4718. (doi:10.1210/jc.2007-1184)

Castellone MD \& Santoro M 2008 Dysregulated RET signaling in thyroid cancer. Endocrinology and Metabolism Clinics of North America 37 363-374, viii. (doi:10.1016/j.ecl.2008.02.006)

Couderc C, Poncet G, Villaume K, Blanc M, Gadot N, Walter T, Lepinasse F, Hervieu V, Cordier-Bussat M, Scoazec JY et al. 2011 Targeting the PI3K/mTOR pathway in murine endocrine cell lines: in vitro and in vivo effects on tumor cell growth. American Journal of Pathology $\mathbf{1 7 8}$ 336-344. (doi:10.1016/j.ajpath.2010.11.023)

Dadon T, Ball D \& Nelkin BD 2013 Misidentification of putative medullary thyroid cancer cell lines RO-H85-1 and RO-D81-1. Journal of Clinical Endocrinology and Metabolism 98 954-955. (doi:10.1210/jc.2012-4181)

de Groot JW, Links TP, Plukker JT, Lips CJ \& Hofstra RM 2006 RET as a diagnostic and therapeutic target in sporadic and hereditary endocrine tumors. Endocrine Reviews 27 535-560. (doi:10.1210/er.2006-0017)

Grozinsky-Glasberg S, Rubinfeld H, Nordenberg Y, Gorshtein A, Praiss M, Kendler E, Feinmesser R, Grossman AB \& Shimon I 2010 The rapamycin-derivative RAD001 (everolimus) inhibits cell viability and interacts with the Akt-mTOR-p70S6K pathway in human medullary thyroid carcinoma cells. Molecular and Cellular Endocrinology 315 87-94. (doi:10.1016/j.mce.2009.09.027)

Jin N, Jiang T, Rosen DM, Nelkin BD \& Ball DW 2011 Synergistic action of a RAF inhibitor and a dual PI3K/mTOR inhibitor in thyroid cancer. Clinical Cancer Research 17 6482-6489. (doi:10.1158/1078-0432.CCR11-0933)

Koh YW, Shah MH, Agarwal K, McCarty SK, Koo BS, Brendel VJ, Wang C, Porter K, Jarjoura D, Saji M et al. 2012 Sorafenib and Mek inhibition is synergistic in medullary thyroid carcinoma in vitro. Endocrine-Related Cancer 19 29-38. (doi:10.1530/ERC-11-0155)

Kunnimalaiyaan M, Ndiaye M \& Chen H 2006 Apoptosis-mediated medullary thyroid cancer growth suppression by the PI3K inhibitor LY294002. Surgery 140 1009-1014 (discussion 1014-1005). (doi:10.1016/j.surg.2006.06.040)

Kurzrock R, Sherman SI, Ball DW, Forastiere AA, Cohen RB, Mehra R, Pfister DG, Cohen EE, Janisch L, Nauling F et al. 2011 Activity of XL184 (Cabozantinib), an oral tyrosine kinase inhibitor, in patients with medullary thyroid cancer. Journal of Clinical Oncology 29 2660-2666. (doi:10.1200/JCO.2010.32.4145)
Lam ET, Ringel MD, Kloos RT, Prior TW, Knopp MV, Liang J, Sammet S, Hall NC, Wakely PE Jr, Vasko VV et al. 2010 Phase II clinical trial of sorafenib in metastatic medullary thyroid cancer. Journal of Clinical Oncology 28 2323-2330. (doi:10.1200/JCO.2009.25.0068)

Leboeuf R, Baumgartner JE, Benezra M, Malaguarnera R, Solit D, Pratilas CA, Rosen N, Knauf JA \& Fagin JA 2008 BRAFV600E mutation is associated with preferential sensitivity to mitogenactivated protein kinase kinase inhibition in thyroid cancer cell lines. Journal of Clinical Endocrinology and Metabolism 93 2194-2201. (doi:10.1210/jc.2007-2825)

Maiso P, Liu Y, Morgan B, Azab AK, Ren P, Martin MB, Zhang Y, Liu Y, Sacco A, Ngo H et al. 2011 Defining the role of TORC1/2 in multiple myeloma. Blood 118 6860-6870. (doi:10.1182/blood-2011-03-342394)

Missiaglia E, Dalai I, Barbi S, Beghelli S, Falconi M, della Peruta M, Piemonti L, Capurso G, Di Florio A, delle Fave G et al. 2010 Pancreatic endocrine tumors: expression profiling evidences a role for AKT-mTOR pathway. Journal of Clinical Oncology 28 245-255. (doi:10.1200/JCO.2008.21.5988)

Powell DJ Jr, Russell J, Nibu K, Li G, Rhee E, Liao M, Goldstein M, Keane WM, Santoro M, Fusco A et al. 1998 The RET/PTC3 oncogene: metastatic solid-type papillary carcinomas in murine thyroids. Cancer Research 58 5523-5528.

Rapa I, Saggiorato E, Giachino D, Palestini N, Orlandi F, Papotti M \& Volante M 2011 Mammalian target of rapamycin pathway activation is associated to RET mutation status in medullary thyroid carcinoma. Journal of Clinical Endocrinology and Metabolism 96 2146-2153. (doi:10.1210/jc.2010-2655)

Robinson BG, Paz-Ares L, Krebs A, Vasselli J \& Haddad R 2010 Vandetanib (100 mg) in patients with locally advanced or metastatic hereditary medullary thyroid cancer. Journal of Clinical Endocrinology and Metabolism 95 2664-2671. (doi:10.1210/jc.2009-2461)

Samadi AK, Bazzill J, Zhang X, Gallagher R, Zhang H, Gollapudi R, Kindscher K, Timmermann B \& Cohen MS 2012 Novel withanolides target medullary thyroid cancer through inhibition of both RET phosphorylation and the mammalian target of rapamycin pathway. Surgery 152 1238-1247. (doi:10.1016/j.surg.2012.08.031)

Sarbassov DD, Guertin DA, Ali SM \& Sabatini DM 2005 Phosphorylation and regulation of Akt/PKB by the rictor-mTOR complex. Science $\mathbf{3 0 7}$ 1098-1101. (doi:10.1126/science.1106148)

Schweppe RE, Klopper JP, Korch C, Pugazhenthi U, Benezra M, Knauf JA, Fagin JA, Marlow LA, Copland JA, Smallridge RC et al. 2008 Deoxyribonucleic acid profiling analysis of 40 human thyroid cancer cell lines reveals cross-contamination resulting in cell line redundancy and misidentification. Journal of Clinical Endocrinology and Metabolism 93 4331-4341. (doi:10.1210/jc.2008-1102)

Wells SA Jr, Robinson BG, Gagel RF, Dralle H, Fagin JA, Santoro M, Baudin E, Elisei R, Jarzab B, Vasselli JR et al. 2012 Vandetanib in patients with locally advanced or metastatic medullary thyroid cancer: a randomized, double-blind phase III trial. Journal of Clinical Oncology 30 134-141. (doi:10.1200/JCO.2011.35.5040)

Yao JC, Shah MH, Ito T, Bohas CL, Wolin EM, Van Cutsem E, Hobday TJ, Okusaka T, Capdevila J, de Vries EG et al. 2011 Everolimus for advanced pancreatic neuroendocrine tumors. New England Journal of Medicine 364 514-523. (doi:10.1056/NEJMoa1009290)

Received in final form 28 June 2013

Accepted 3 July 2013

Made available online as an Accepted Preprint

4 July 2013 http://erc.endocrinology-journals.org DOI: 10.1530/ERC-13-0085
(C) 2013 Society for Endocrinology Printed in Great Britain 